\title{
MICROMORPHOLOGY AND SYSTEMATIC DISTRIBUTION OF PIT MEMBRANE THICKENINGS IN OLEACEAE: TORI AND PSEUDO-TORI
}

\author{
David Rabaey $^{1}$, Suzy Huysmans ${ }^{1}$, Frederic Lens ${ }^{1}$, Erik Smets ${ }^{1,2}$ and \\ Steven Jansen ${ }^{3}$
}

\begin{abstract}
SUMMARY
Recent studies on the functional significance of pit membranes in water conducting cells have renewed general interest in their micromorphology. At least two types of pit membrane thickenings have been described in angiosperm families, i.e. genuine tori and pseudo-tori. This study explores the distribution and morphology of pit membrane thickenings in 69 species and 23 genera within Oleaceae using light and electron microscopy. Torus-bearing pit membranes are confirmed for Osmanthus, and new records are reported for Chionanthus retusa, Picconia azorica, and P. excelsa, but not for the other species studied of Chionanthus. This infrageneric variation suggests that tori represent a plastic feature that has evolved more than once within the family as the result of functional adaptation to efficient and safe water transport. Pseudo-tori are observed in species of Abeliophyllum, Fontanesia, Forsythia, Jasminum, Ligustrum, Menodora, and Syringa. Based on structural differences, we state that tori and pseudo-tori can be distinguished as non-homologous features.
\end{abstract}

Key words: Electron microscopy, pit aperture, pit membrane, plasmodesmata, pseudo-torus, torus, tracheid, vessel element.

\section{INTRODUCTION}

Recently, the interest in pit morphology has been renewed by physiological experiments that illustrate the importance of pit membranes in the hydraulic system of plants (Choat et al. 2003, 2004, 2006, 2008; Pitterman et al. 2005; Wheeler et al. 2005). Most angiosperm pit membranes possess a homogeneous pit membrane, while the majority of conifer pit membranes show a central thickening or 'torus' surrounded by a highly porous margo. Pit membrane pores in angiosperms are usually very small, with the average pore diameter around $5 \mathrm{~nm}$, although the maximum pore diameter may reach more than $100 \mathrm{~nm}$ (Choat et al. 2003, 2004, 2008; Sano 2005). Conifers, however, are known to show pore sizes commonly up to $200 \mathrm{~nm}$ in diameter (Liese \& Johann 1954). Although these differences hold true for most of the angiosperms and gymnosperms,

1) Laboratory of Plant Systematics, Institute of Botany and Microbiology, Kasteelpark Arenberg 31, P.O. Box 2437, 3001 Leuven, Belgium.

2) National Herbarium of the Netherlands, Leiden University branch, P.O. Box 9514, 2300 RA Leiden, The Netherlands.

3) Jodrell Laboratory, Royal Botanic Gardens, Kew, TW9 3DS, Richmond, Surrey, United Kingdom. 
there seems to be considerably more variation in pit membrane morphology than generally assumed. Recent studies on the morphology of pits revealed a large structural variation, especially with respect to pore size, pit membrane thickness, and presence of a pit membrane 'thickening' (Dute et al. 2001, 2004; Jansen et al. 2004a, b; Sano 2005; Rabaey et al. 2006; Sano \& Jansen 2006; Jansen pers. comm.). Since pit membranes are responsible for more than $50 \%$ of total xylem hydraulic resistance and strongly influence vulnerability to embolism, it is expected that modifications of the pit membrane structure are correlated with trade-offs between efficiency and safety of water transport (Choat et al. 2004, 2006; Pitterman et al. 2005).

The first report of a non-homogeneous pit membrane in angiosperms included the description of a torus-margo configuration in Daphne (Thymelaeaceae) and Osmanthus (Oleaceae) (Ohtani \& Ishida 1978). Since then, tori have been found in representatives of Cannabaceae, Rosaceae, and Ulmaceae (Wheeler 1983; Dute \& Rushing 1990; Dute et al. 1992, 2001, 2004; Jansen et al. 2004a, 2007). A second type of pit membrane thickening in angiosperms was first found in Ribes sanguineum (Grossulariaceae) by Parameswaran and Liese (1973), who described anomalous, pad-like structures associated with pit membranes of fibre-tracheids. Similar thickenings have been found in Elaeagnaceae, Ericaceae, Oleaceae, Rhamnaceae, and Rosaceae, and transmission electron microscopic observations (TEM) illustrated that this type of thickening is associated with plasmodesmata (Parameswaran \& Vidal Gomes 1981; Barnett 1982, 1987a, b; Lachaud \& Maurousset 1996; Rabaey et al. 2006; Jansen et al. 2007). Because this feature looks similar to a genuine torus when using light microscopy (LM), the term pseudo-torus was introduced (Rabaey et al. 2006).

Oleaceae constitute an interesting angiosperm family to study pit membrane thickenings, because the family includes not only records of tori in Osmanthus, but also thickenings reported in Ligustrum that look very similar to pseudo-tori (Parameswaran \& Vidal Gomes 1981). It is likely that additional records of tori can be found in Oleaceae because their presence has simply been overlooked in previous studies. Indeed, tori seem to be associated with other wood anatomical characters that occur in this family, for instance helical thickenings, round apertures, vasicentric tracheids, and ring-porosity (Baas et al. 1988; Jansen et al. 2004a). This paper aims to investigate the distribution and morphology of pit membrane thickenings in Oleaceae. Light and electron microscopy of a wide range of genera will help us to determine whether or not pseudo-tori occur in Oleaceae, and how often pit membrane thickenings have evolved within this family.

\section{MATERIAL AND METHODS}

A total number of 84 Oleaceae specimens out of 23 genera was studied using LM and scanning electron microscopy (SEM). TEM was used to investigate the ultrastructure of pit membranes in Chionanthus retusa, Ligustrum devalayanum, and L. obtusifolium.

For LM and SEM wood samples were used from the Kew herbarium (K), the wood collection of Kew (Kw), the living collections of the Royal Botanic Gardens, Kew (RBG, Kew), the wood collection of Tervuren (Tw), and the herbarium (BR) and living collections of the National Botanic Garden of Belgium. For TEM, young stem 
segments were collected from the living collections of the National Botanic Garden of Belgium. The nomenclature of all species follows the International Plant Names Index (http://www.ipni.org). The following species were investigated with reference to their origin and collectors:

Abeliophyllum distichum Nakai: U.K. (RBG, Kew; 2002-411) - Chionanthus africanus Welw. ex Gilg \& G.Schellenb.: Democratic Republic Congo, J. Lejoly 96/970 (BR); C. battiscombei (Hutch.) Stearn: Democratic Republic Congo, F. Malaisse 13022 (BR); C. compacta Sw.: French Antilles, Guadeloupe, Ducos (Tw 50116); C. curvicarpus Kiew: Brunei (Kw 74848); C. laxiflora Blume: Brunei (Kw 74366); C. pachyphyllus (Merr.) Kiew: Brunei (Kw 74568); C. pluriflorus (Knobl.) Kiew: Brunei (Kw 74825); C. ramiflorus Roxb.: India, R.F. Holemacher (BR); C. retusa Paxt.: New York, Mori \& Gracie 23042 (K); Belgium (living collection BR; 19921859-96); C. virginica L.: Belgium (living collection BR; 19380694) - Comoranthus sp.: Madagascar, Itamboro, P.B. Phillipson 2751 (BR); C. minor H.Perrier: Madagascar, R. Capuron et F. Chauvert 20.785 SF (BR) - Fontanesia fortunei Carrière: U.K. (RBG, Kew; 1979-6639); F. phillyraeoides Labill.: U.K. (RBG, Kew; 1979-6639) - Forestiera acuminata Poir.: USA, Arkansas, H. Nogle (Tw 18323); F. neo-mexicana A.Gray: U.K. (RBG, Kew; 1982-2697) - Forsythia $\times$ intermedia Zabel: U.K. (RBG, Kew; 1973-17767); F. suspense Vahl: Belgium, Brabant, R. Deschamps (Tw 26308) - Fraxinus excelsior L.: Belgium, D. Rabaey - Haenianthus salicifolius Griseb.: Puerto Rico, Cerro La Santa, Carite Forest, 3000 m, R.A. Hovard 16833 (BR) - Jasminum dichotomum Vahl: Angola, Malanje, R. Deschamps (Tw 28566); J. fruticans L.: France, Ardeche, R. Deschamps (Tw 47175); J. humile L.: U.K. (RBG, Kew; 1972-2110) - Ligustrum sp.: Malaysia, Malaya (Kw 22893); L. sp.: U.K. (RBG, Kew; 1991-2307); L. amurense Carrière: USA, Texas, H. Nogle (Tw 18326); L. compactum Hook. f. \& Thomson ex Decne.: India, Jaunsar (Kw 22891); L. devalayanum Har.: U.K. (RBG, Kew; 19888484); Belgium (living collection BR; 10002001); L. foliosum Nakai: U.K. (RBG, Kew; 1989-8337); L. ibolium Coe ex Rehder: U.K. (RBG, Kew; 1973-211136); L. ibota Siebold: USA, Louisiana, A.N. Green (Tw 36083); L. ionandrum Diels: U.K., Kew (Kw 12726); L. japonicum Thunb.: USA, Texas (Kw 12727); L. lucidum W.T. Aiton: U.K. (RBG, Kew; 161-7906680); Belgium (living collection BR; 19761007); L. microcarpum Kaneh. \& Sasaki: U.K. (RBG, Kew; 2002-1979); L. obtusifolium Siebold: U.K. (RBG, Kew; 1978-6464); Belgium (living collection BR; 19811711); L. ovalifolium Hassk.: U.K. (Kw 71687); U.K. (RBG, Kew; 1982-6144); L. pacificum Nakai: Japan, Gov. For. Exp. Slat. (Tw 23397); L. quihoi Carrière: U.K. (RBG, Kew; 1995-1650); L. robustum (Roxb.) Blume: Burma (Kw 12731); L. sempervirens Lingelsh.: U.K., Kew (Kw 72227); L. sinense Lour.: U.K., Kew (Kw 12732); L. sinense Lour.: Belgium (living collection BR; 19911226-36); L. strongylophyllum Hemsl.: Belgium (living collection BR; 19931279-10); L. tschonoskii Decne.: U.K. (RBG, Kew; 1999-3365); L. $\times$ vicaryi Rehder: Belgium (living collection BR; 19880230); L. vulgare L.: U.K. (RBG, Kew; 1969-5514) - Menodora scabra A. Gray: USA, Arizona, W.F. Parish (BR); M. spinescens A. Gray: USA, Mohave Desert, M.F. Spencer (BR) - Myxopyrum ovatum A.W. Hill: New Guinea, R. Schlechter (BR); M. nervosum Blume: Philippines, M. Ramos \& G. Edaño 8-373 (BR) - Nestegis cunninghamii (Hook.f.) L.A.S. Johnson: 
New Zealand, A.N. Green (Tw 44484) - Noronhia emarginata (Lam.) Poir.: USA, Hawaii, A. Curtis (Tw 53245); N. humbertiana H. Perrier: Madagascar, R. Capuron 23119-SF (BR) - Notelaea ligustrina Sieber ex Benth.: Australia, Tasmania, Forestry Service (Tw 17027) - Nyctanthes arbor-tristis L.: Belgium (living collection BR; 19764149) - Olea europaea L.: U.K. (RBG, Kew; 2005-1588); O. lanceolata Hook. f.: New Zealand, A.N. Green (Tw 19902); O. welwitschii Gilg \& G. Schellenb.: Zambia, FHOW Oxford Forestry Institute Xylarium (Tw 39094) - Osmanthus fragrans Lour.: China, Hong Kong, Hu \& Yang $566(\mathrm{~K})$ - Phillyrea angustifolia L.: Italy, Venice, G. Rigo (BR); P. angustifolia L.: France, M. Couteaux 70SE219 (BR); P. latifolia L.: S Algeria (Kw 12872); Spain, Mallorca, J. Duvigneaud (BR 614147); U.K. (RBG, Kew; 305-6830504); P. media L.: Portugal, Estremadun, Gomes (K); Israel (Kw 12874); P. stricta Bertol.: Italy, Venice, Rigo (K); Italy (BR) - Picconia azorica (Tutin) Knobl.: Portugal, Azores, H.C.Watson (BR); P. excelsa DC.: Spain, La Palma, Hunnay (K); Spain, La Palma, J. Bornmüller (BR) - Priogymnanthus apertus (B. Stahl) P. S. Green: Peru, Lambayeque, Quiroz 3336 H/2000/02043 18 (K); P. hass-lerianus (Chodat) P.S. Green: Brazil, Plowran et al. 8357 H/1274/94 (K) - Schrebera alata Welw.: Rwanda, G. Troupin (Tw 26052); S. arborea A. Chev. \& A. Chev.: Senegal, Casamance, J. De Wolf (Tw 53973); S. golugensis Welw.: Guinea, Bissau, Barreiros Dos Rei, J.E. (Tw 27542); S. trichoclada Welw.: Angola, Benguela, R. Deschamps (Tw 28197) - Syringa sweginzowii Koehne \& Lingelsh.: U.K. (RBG, Kew; 1994-1260).

\section{Light microscopy}

All wood samples were investigated using light microscopy. Preparation of the wood samples was according to standard techniques as described in Jansen et al. (1998). Thin sections (10-15 $\mu \mathrm{m}$ ) were prepared using a sliding microtome (Reichert, Vienna, Austria). A mixture of safranin and alcian blue $(35: 65, \mathrm{v} / \mathrm{v})$ was used as staining solution. After staining, sections were washed with distilled water, dehydrated with ethanol and treated with clearing agent Parasolve (Prosan, Merelbeke, Belgium). The sections were embedded in Euparal (Agar Scientific Ltd, Essex, UK). LM-observations were carried out with a Dialux 20 (Leitz, Wetzlar, Germany) fitted with an oil immersion objective. Digital images were made with a PixeLINK PL-B622CF camera.

\section{Scanning electron microscopy}

Small blocks ( $\pm 3 \mathrm{~mm}$ thick) were cut and attached to stubs using electron-conductive carbon paste. The samples were sputter coated for 3 min either with gold (Spi-Supplies, West Chester, Pennsylvania, USA) or with platinum using an EMITECH K550 sputter coater (Emitech Ltd., Ashford, U.K.). Observations were carried out at the Laboratory of Plant Systematics (K.U. Leuven) with a Jeol JSM 6360 SEM (Jeol Ltd., Tokyo, Japan) at $15 \mathrm{kV}$ and with a Hitachi S-4700 field-emission SEM (Hitachi High Technologies Corp., Tokyo, Japan) at $2 \mathrm{kV}$ at the Jodrell Laboratory (RBG, Kew).

\section{Transmission electron microscopy}

TEM observations were made on Chionanthus retusa, Ligustrum devalayanum and L. obtusifolium. Fresh wood samples from one- to two-year-old branches were col- 
lected at BR. Small segments from thin branches were cut into $2 \mathrm{~mm}^{3}$ pieces and fixed overnight in $2 \%$ glutaraldehyde at $\mathrm{pH} 7.4$, buffered with $0.05 \mathrm{M}$ sodium cacodylate at room temperature. After washing in $0.05 \mathrm{M}$ sodium cacodylate buffer, the specimens were postfixed in $1 \%$ buffered osmium tetroxide for 4 hours at room temperature, washed, and dehydrated through a graded ethanol series. The ethanol was gradually replaced with LR-White resin (London Resin Co, Reading, U.K.) over several days. The resin was polymerized at $60{ }^{\circ} \mathrm{C}$ for 24 hours. Embedded samples were trimmed and sectioned with an ultramicrotome (Ultracut E, Reichert-Jung, Austria). Semi-thin sections cut with a glass knife were heat-fixed to glass slides, stained with $0.5 \%$ toluidine blue in 0.1 M phosphate buffer and mounted in DPX (Agar Scientific, Stansted, UK). Ultra-thin sections $( \pm 90 \mathrm{~nm})$ were cut using a diamond knife. The sections were attached to Formvar coated grids and stained with uranyl acetate and lead citrate using a LKB 2168 Ultrostainer (LKB-Produkter AB, Bromma, Sweden). Observations were carried out using a Zeiss EM 900 microscope at $80 \mathrm{kV}$ accelerating voltage.

Terminology follows the IAWA Committee (1989). Quantitative characters were measured using Carnoy 2.1 (Schols et al. 2002) and were based on 25 counts for each character.

\section{RESULTS}

\section{Distribution of pit membrane thickenings}

The presence of pit membrane thickenings can be easily overlooked by LM. Even when using a $100 \times$ oil-immersion objective on thin sections stained with safranin and alcian blue, it is difficult to discern thickenings and to determine their true nature. Nonetheless, pit membrane thickenings are found in 30 species studied (Table 1). However, most of the genera have homogeneous pit membranes: Comoranthus, Forestiera, Fraxinus, Haenianthus, Myxopyrum, Nestegis, Noronhia, Notelaea, Nyctanthes, Olea, Phillyrea, Priogymnanthus, and Schrebera (Fig. 1, 5). Pit membrane thickenings appear most commonly in bordered pits of small tracheary elements (Fig. 2, 3). Their

Table 1. List of species studies with pit membrane thickenings. Species not listed have homogeneous pit membranes.

\begin{tabular}{|l|l|}
\hline Species with tori & Species with pseudo-tori \\
\hline Chionanthus retusa & Abeliophyllum distichum \\
Osmanthus fragrans & Fontanesia fortunei, F. phillyraeoides \\
Picconia azorica, P. excelsa & Forsythia $\times$ intermedia \\
& Jasminum fruticans \\
& Ligustrum amurense, L. compactum, L. devalayanum, L. foliosum, \\
& L. ibolium, L. ibota, L. ionandrum, L. japonicum, L. lucidum, \\
& L. microcarpum, L. obtusifolium, L. ovalifolium, L. quihoi, L. sinense, \\
& L. strongyllophyllum, L. tschonoskii, L. $\times$ vicaryi, L. vulgare \\
& Menodora scabra, M. spinescens \\
& Syringa sweginzowii \\
\hline
\end{tabular}



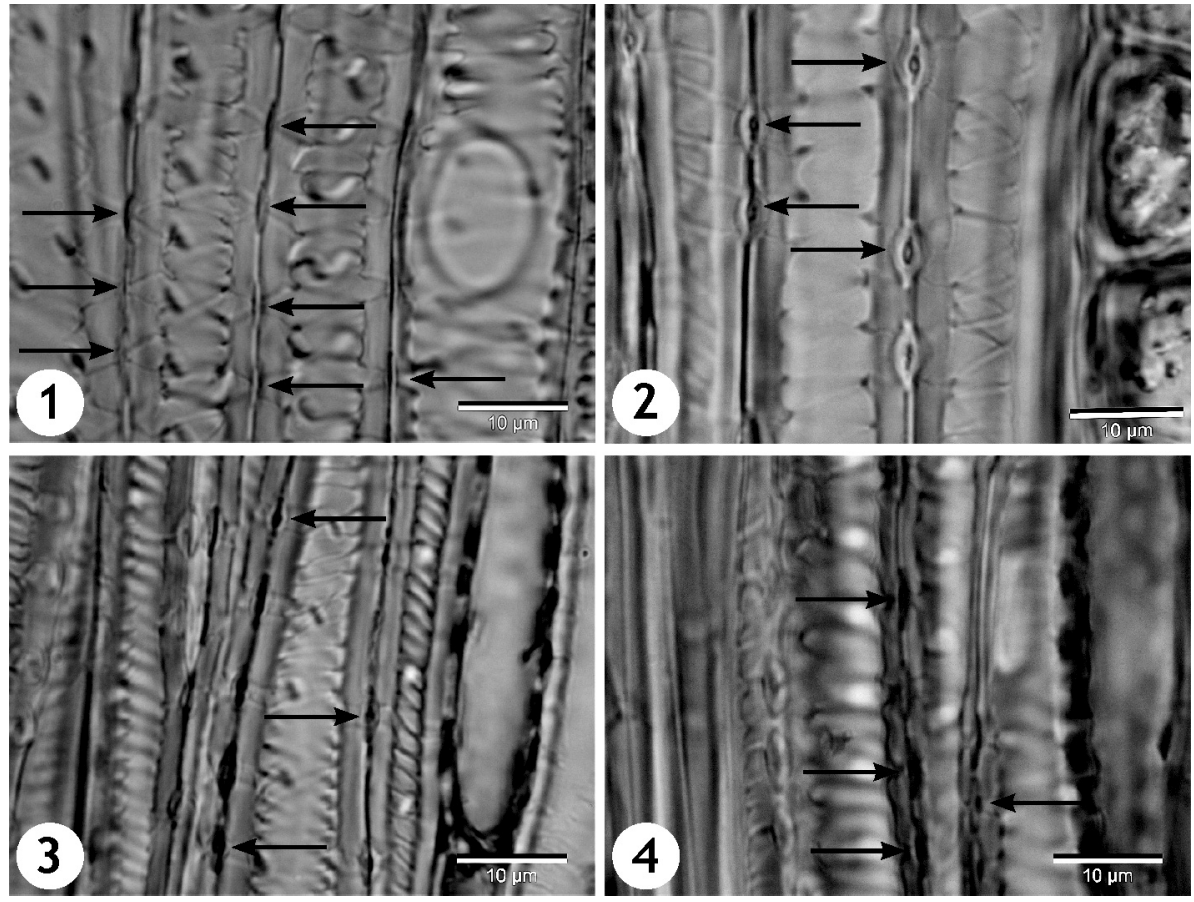

Figures 1-4. Pit membranes in Oleaceae (LM). - 1: Phillyrea latifolia. Longitudinal section showing bordered pits with homogeneous pit membranes (arrows). - 2: Ligustrum sinense. Longitudinal section showing narrow tracheary elements with bordered pits with pseudo-tori (arrows). - 3: Menodora scabra. Longitudinal section with various pseudo-tori in narrow tra cheary elements (arrows). - 4: Picconia excelsa. Longitudinal section showing tori on every pit membrane in vasicentric tracheids (arrows).

Figures 5-12. Pit membrane thickenings in Oleaceae (SEM). - 5: Olea europaea. Two homogeneous pit membranes in small tracheary elements. - 6: Syringa sweginzowii. Detail of a pit membrane of small tracheary element bearing a pseudo-torus. - 7: Ligustrum japonicum. Pseudotorus (arrow) on one pit membrane of a tracheary element. - 8: Menodora scabra. Overview of pit membranes of narrow vessel elements bearing pseudo-tori (arrow). -9: Osmanthus fragrans. Detail of pit membrane of vasicentric tracheid bearing a torus $(\mathrm{T})$ and a loose textured margo (M). The microfibrils in the margo are oriented radially. - 10: Picconia excelsa. Detail of pit membrane of vasicentric tracheid bearing a torus (T) and a margo (M). The annulus (A) is visible at the outline of the pit membrane. - 11: Picconia azorica. Overview of pit membrane of vasicentric tracheid bearing a torus (arrows). - 12: Chionanthus retusa. Detail of pit membrane bearing a torus (T) and margo (M). 

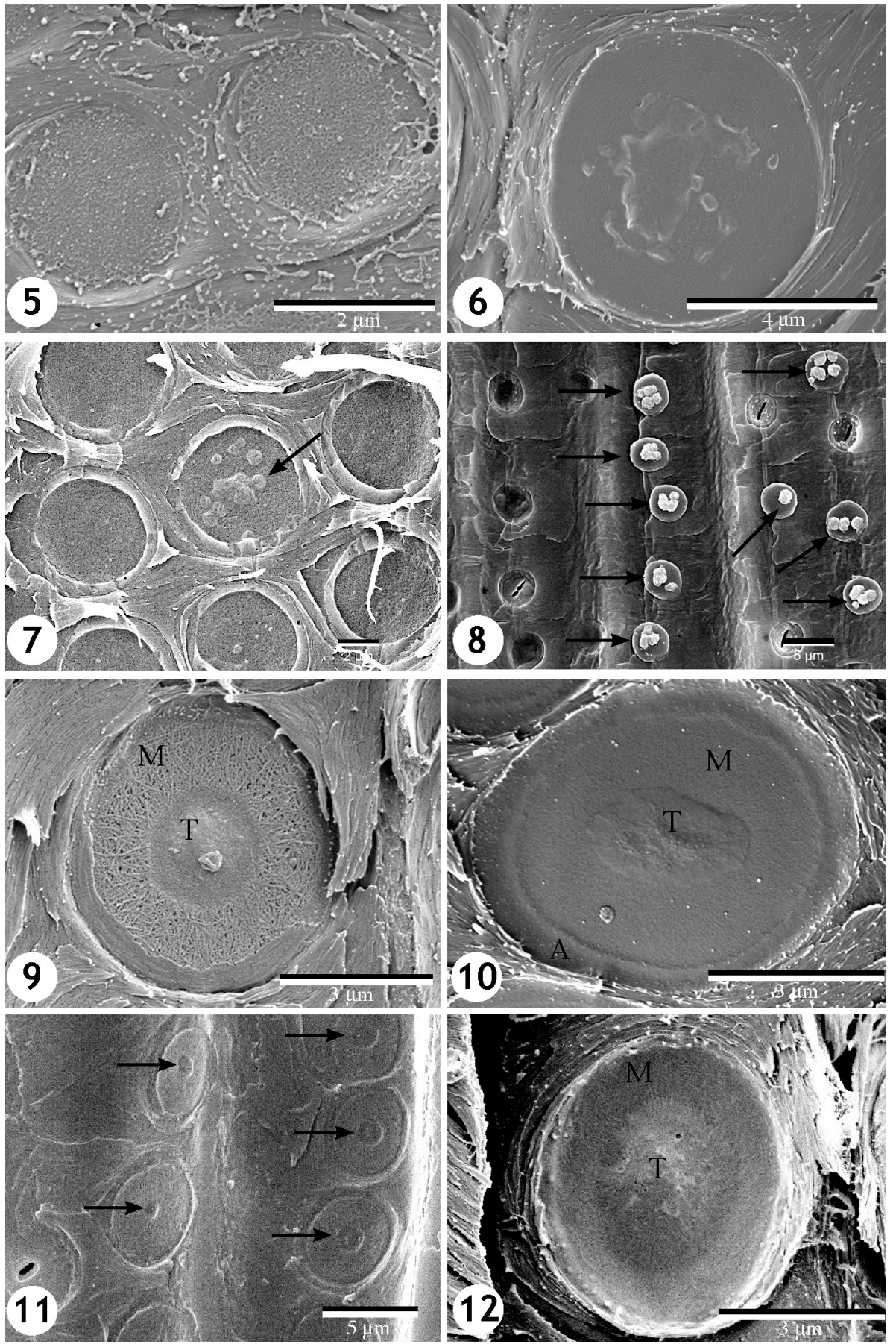
distribution does not show any difference between latewood and earlywood, or between tangential and radial walls. Pits in vessel elements $>20 \mu \mathrm{m}$ in tangential diameter seem to lack thickenings.

Most of the thickenings associated with pit membranes have a brownish, sometimes transparent, appearance, and a rounded to cap-like structure under LM (Fig. 2, 3). The distribution of these pseudo-tori is inconsistent, i.e. not all bordered pits of a particular cell type show pit membrane thickenings. In addition, the thickenings appear in various cell types. Occasionally, more than one thickening was present on a single pit membrane. The cells associated with these pit membrane thickenings show only sporadically helical thickenings and have oval to slit-like outer pit apertures.

Thickenings found in Chionanthus retusa, Osmanthus fragrans, Picconia azorica, and $P$. excelsa, however, differ from those found in the other Oleaceae species studied (Fig. 4). They appear as blue-stained, lens-shaped structures, and are associated with all pits within vasicentric tracheids and narrow vessels. The small tracheary elements in species with this type of pit membrane thickening show helical thickenings and inner pit apertures are circular to oval in outline with mean circularity ratios from 0.41 $\mu \mathrm{m}$ in $P$. azorica to $0.66 \mu \mathrm{m}$ in $C$. retusa (Table 2). Tori are often associated with the presence of helical thickenings and round pit apertures.

Table 2. Quantitative pit characters of the Oleaceae species with torus-bearing pit membranes.

\begin{tabular}{ccccc}
\hline & Chionanthus retusa & Osmanthus fragrans & Picconia azorica & Picconia excelsa \\
\hline 1 & $1.43-(2.19)-2.88$ & $1.56-(2.14)-2.88$ & $0.58-(0.93)-1.45$ & $1.44-(2.37)-3.46$ \\
2 & $1.37-(2.03)-3.16$ & $1.16-(1.80)-2.30$ & $0.61-(1.00)-1.43$ & $1.55-(2.18)-2.74$ \\
3 & $0.57-(0.85)-0.98$ & $0.63-(0.83)-1.00$ & $0.39-(0.80)-1.00$ & $0.61-(0.81)-0.99$ \\
4 & $0.90-(1.51)-2.07$ & $0.93-(1.42)-1.90$ & $1.11-(1.43)-1.91$ & $1.19-(1.88)-2.46$ \\
5 & $0.68-(1.00)-1.65$ & $0.58-(0.79)-1.13$ & $0.38-(0.58)-0.75$ & $0.63-(0.87)-1.34$ \\
6 & $0.47-(0.66)-0.91$ & $0.39-(0.57)-0.76$ & $0.26-(0.41)-0.51$ & $0.34-(0.47)-0.91$ \\
7 & $3.42-(4.82)-6.48$ & $2.86-(3.86)-4.92$ & $3.16-(3.98)-4.59$ & $4.28-(5.10)-6.50$ \\
\hline
\end{tabular}

$1=$ vertical torus diameter $(\mu \mathrm{m})-2=$ horizontal torus diameter $(\mu \mathrm{m})-3=$ mean circularity ratio of torus $(\mu \mathrm{m})-4=$ vertical diameter of outer pit aperture $(\mu \mathrm{m})-5=$ horizontal diameter of outer pit aperture $(\mu \mathrm{m})-6=$ circularity ratio of outer pit aperture $(\mu \mathrm{m})-7=$ horizontal diameter of pit chamber $(\mu \mathrm{m})$.

\section{Morphology of pit membrane thickenings}

Using SEM observations, a more profound morphological difference can be seen between pseudo-tori (Fig. 6-8), and genuine tori (Fig. 9-12). Species with pseudo-tori show pit membranes with and without thickenings within the same cell (Fig. 7). The density and size of these pseudo-tori differ significantly within a single species (Fig. 8). Most of these thickenings have the following characteristics: 1) a composition of several cores, 2) an irregular outline (Fig. 6, 7), and 3) an eccentric location on the pit membrane (Fig. 6-8). Microfibrils in the pit membrane are randomly to radially distributed. Genuine tori, which were observed in our sampling in Chionanthus, Osmanthus, and 

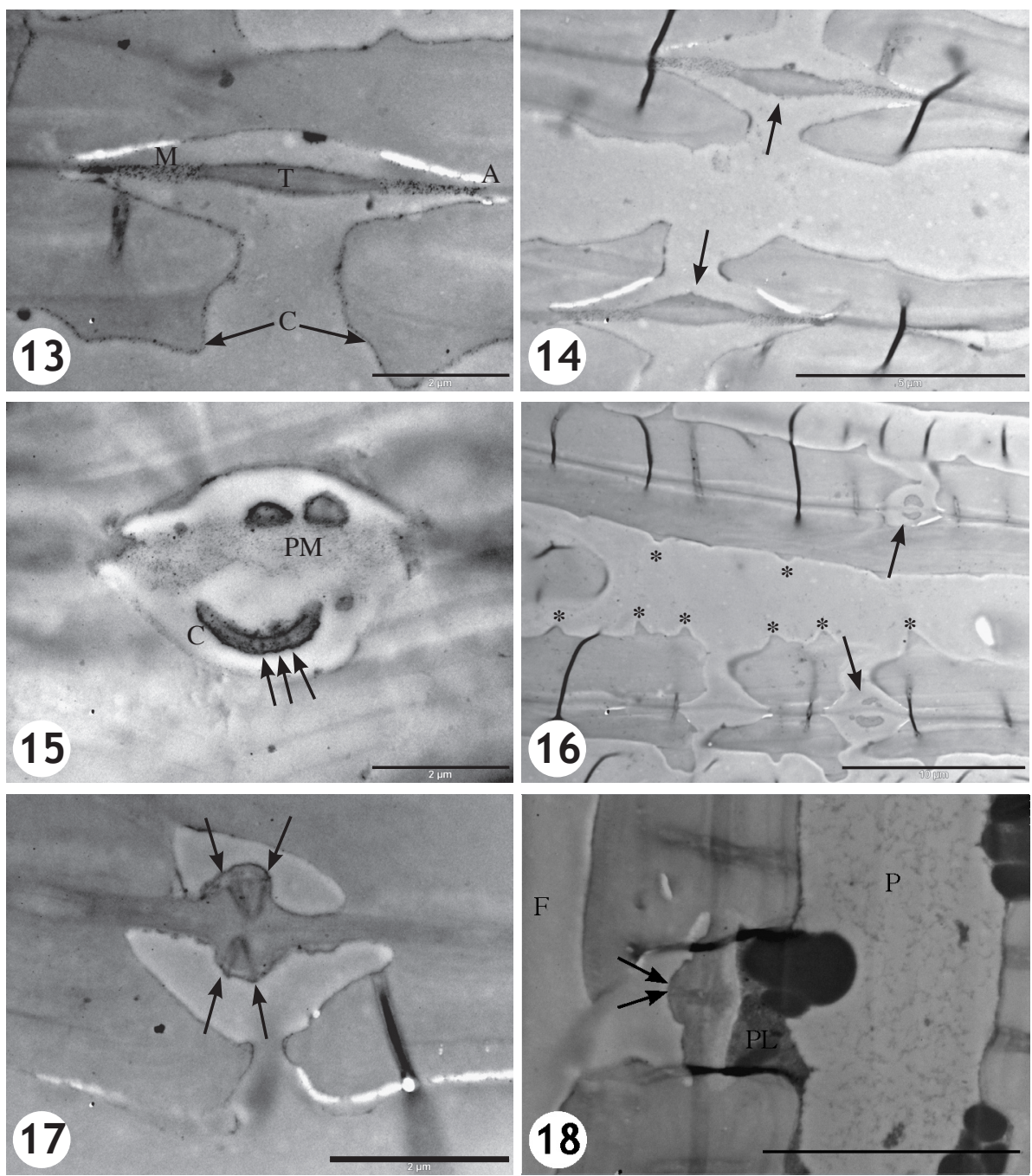

Figures 13-18. Longitudinal sections showing pit membrane thickenings in Oleaceae (TEM). 13: Chionanthus retusa. Detail of a pit membrane bearing a torus (T), a margo (M) and an annulus (A) at the periphery of the pit membrane. A thin electron dense coating is visible (C). 14: Chionanthus retusa. Overview of small tracheary element showing a torus (arrows) on both pit membranes. - 15: Ligustrum obtusifolium. Detail of pit membrane with pseudo-torus. The pit membrane (PM) is hydrolysed and the cap (C) is persistent. Plasmodesmata remnants (arrows) are visible in the cap. - 16: Ligustrum devalayanum. Overview of small tracheary elements showing some pit membranes with pseudo-torus (arrow). Helical thickenings $(*)$ are present in the small tracheary elements. - 17: Ligustrum obtusifolium. Detail of pit membrane with young pseudo-torus. Plasmodesmata (arrows) are present within the thickening. - 18: Ligustrum obtusifolium. Detail of half-bordered pits of tracheid (T)-parenchyma (P) showing a pit membrane with a pseudo-torus at the tracheid side. A protective layer (PL) is present at the side of the parenchyma. 
Picconia, show a round to oval structure with a mean circularity ratio between 0.80 and 0.85 (Table 2). The torus diameter is wider than the aperture for (Fig. 13), with the mean horizontal diameter of the torus varying from 1.00 to $2.18 \mu \mathrm{m}$ in P. azorica and $P$. excelsa, respectively. The mean horizontal axis of the outer pit aperture varies between 0.58 and $1.00 \mu \mathrm{m}$ (Table 2). This is very clear for C. retusa, O. fragrans and P. excelsa. The tori present in P. azorica are remarkably small compared with the former three (Table 2). Tori are consistently associated with all pits in a single cell (Fig. 11). Tori are sometimes oval (Fig. 10), reflecting the outline of the inner pit aperture. The microfibrils of the margo show a radial orientation.

\section{Ultrastructure of pit membrane thickenings (TEM)}

A central torus, which is observed in Chionanthus retusa, is usually visible on both sides of a pit pair and is more electron-dense than the remainder of the pit membrane. Tori are wider than the outer pit apertures. The margo has a similar appearance as homogeneous pit membranes in vessel elements (Fig. 13). A pit membrane annulus occurs in both homogeneous and torus-bearing pit membranes (Fig. 10, 14). A thin electron-dense coating is visible on the pit chamber, the torus, and the inner secondary cell wall (Fig. 14).

The structure of pseudo-tori found in the two Ligustrum species studied, is shown in Figures 15-18. Two developmental stages of pseudo-tori can be distinguished: 1) "young" pseudo-tori with a solid structure, which usually show plasmodesmata directed to the centre of the thickening (Fig. 17), and 2) fully developed pseudo-tori consisting of an electron dense cap-like layer overlaying a transparent area and showing remnants of plasmodesmata (Fig. 15, 16). The cap-like structure of a young pseudo-torus becomes more electron-dense after hydrolysis, while enzymes remove part of the underlying pit membrane thickening, resulting in a hollow and transparent appearance. No differences were observed in cell development or timing of the developmental stages between cells with or without pseudo-tori. Pseudo-tori are only found in some pit membranes of tracheary elements (Fig. 16). We observed also pseudo-tori in halfbordered pits of tracheid-parenchyma or vessel-parenchyma pit pairs, but then only at the tracheary element side (Fig. 18). In that case, a protective layer occurs at the side of the parenchyma cell.

\section{DISCUSSION}

\section{Oleaceae with torus-bearing pit membranes}

Two types of pit membrane thickenings are present in Oleaceae. The first type, which we only observed in Osmanthus fragrans, Picconia azorica, P. excelsa, and Chionanthus retusa, is interpreted as a genuine torus with a more or less circular thickening that is centrally located on every pit membrane in the same cell. In addition to previous reports of tori in various species of Osmanthus (Ohtani \& Ishida 1978; Dute \& Rushing 1987), the present study demonstrates new records in the genera Picconia and Chionanthus. The wood anatomical characters associated with tori, such as helical thickenings, circular to oval pit apertures, tracheids, and dendritic vessel arrangement occur in these three species and were also reported by earlier studies (Patel 1978; Baas et al. 1988). 
Although all torus-bearing species seem to belong to Group V of Baas et al. (1988), the presence of this set of wood anatomical features does not seem to be an absolute prerequisite for the occurrence of tori, because genera such as Nestegis, Notelaea, and Phillyrea show a similar wood anatomy but do not have tori in the species studied. Although some Olea species also belong to Group V, we were unable to test whether tori occur in these Olea species due to lack of material.

In some genera, the distribution of tori shows interesting variation at species level. As previously suggested for species within Ulmus and related Ulmaceae, tori are more common in temperate climates than in tropical environments (Dute et al. 2004; Jansen et al. 2004). Thus, the ecological and geographical distribution of species within a genus could have influenced the development of a torus. Osmanthus, for instance, includes about 30 species of evergreen plants, mostly native to warm temperate Asia with a distribution from the Caucasus to Japan, although some species also grow in tropical East Asia and one in the USA. Several authors reported the presence of tori in Osmanthus and, as far as we know, all species studied in this genus have tori on the pit membranes of vasicentric tracheids and vessel elements (Ohtani \& Ishida 1978; Dute \& Rushing 1987, 1988). It is unclear, however, whether tori characterize this genus entirely. As for the genus Chionanthus, only two out of the ten species examined in this study show a distribution in temperate areas, namely $C$. retusa and $C$. virginica, whereas the other species show a tropical distribution and were treated in the past as Linociera (Stearn 1976). Interestingly, tori were found in C. retusa, which is native to China, Korea and Japan, but not in C. virginica, which is a tree from North-East

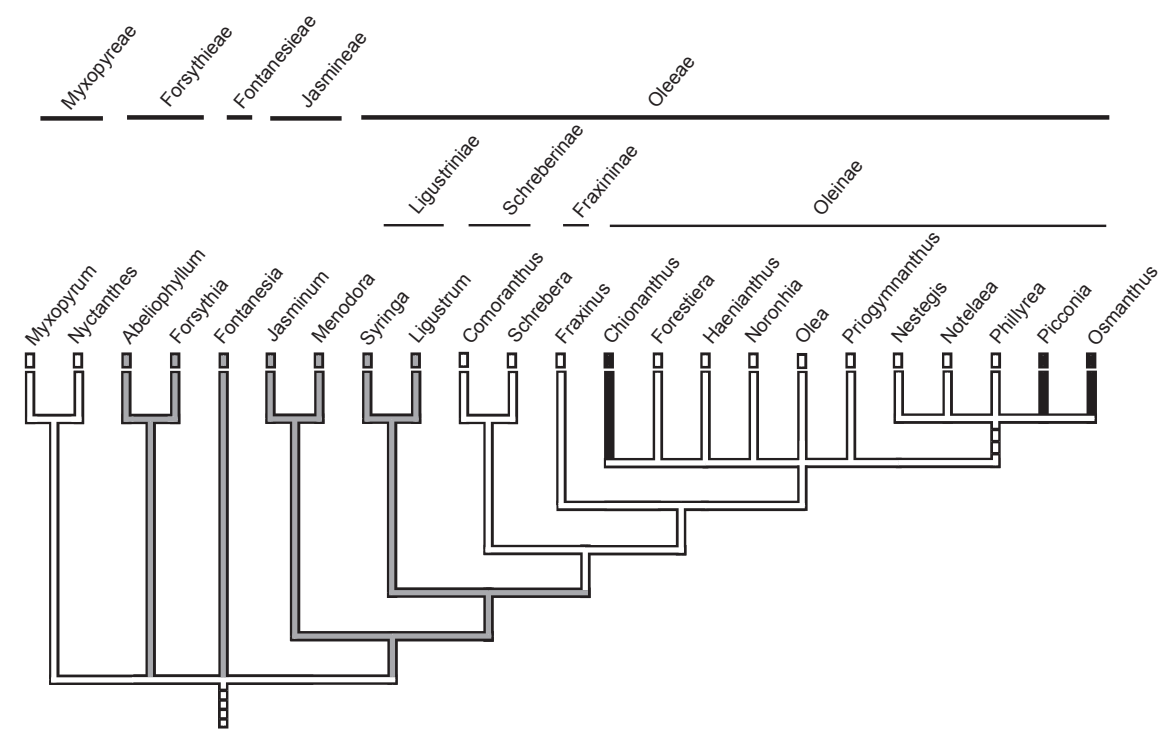

Figure 19. Simplified phylogenetic hypothesis of the Oleaceae based on Wallander \& Albert (2000). Tori-bearing taxa are indicated in black, pseudo-tori-bearing taxa in gray and species with homogeneous pit membranes in white. 
America. It would be interesting to study additional material of $C$. virginica since the absence of tori in the specimen investigated does not support the general idea that tori are inherited as a functional character complex in temperate areas with a seasonally dry period (Jansen et al. 2004). Tori are present in both species of Picconia, which were previously included in Notelaea (Johnson 1957; Green 1968). The distribution of Picconia is restricted to the islands of the Macaronesian archipelago, while all Notelaea species occur in East Australia. At species level tori seem to be consistently present in every specimen of the same species. Tori are observed in two specimens of $C$. retusa and $P$. excelsa and our observations of torus-bearing pits in $O$. fragrans and P. azorica confirm observations of respectively Ohtani and Ishida (1978) and Dute et al. (2008).

According to our results, it seems plausible to assume that tori have developed more than once during the evolution of Oleaceae, with probably one origin of tori in Chionanthus, and at least one in Osmanthus and Picconia (Fig. 19) (Wallander \& Albert 2000; Lee et al. 2007). Dute et al. (1988, 1990) and Coleman et al. (2004) demonstrated that tori in Osmanthus are formed during late developmental stages and become consequently lignified. It would be interesting to know whether tori in Chionanthus are similar to those of Osmanthus in terms of their development and chemical composition. The safraninalcian blue staining used in this study does not show any differences between these genera. Dute et al. (2008) suggested that tori in Picconia and Osmanthus are similar in chemistry based on a similar stain distribution after treatment with $\mathrm{KMnO}_{4}$.

\section{Pseudo-tori in Oleaceae}

The pit membrane thickenings found in 26 Oleaceae species are similar to the pit membrane thickenings reported by Parameswaran and Vidal Gomes (1981) in Ligustrum lucidum and represent pseudo-tori. Characteristic features of pseudo-tori include their irregular distribution, a hollow structure under an electron-dense cap, an asymmetrical outline, and frequently an eccentric location on the pit membrane. The pseudo-tori-bearing species fall within Group I and II sensu Baas et al. (1988) that are characterized by solitary vessels and fibre-tracheids. The reason why pseudo-tori seem to be restricted to Group I and II is most likely due to a fairly strong correlation between pseudo-tori and fibre-tracheids. One exception can be found, however. Myxopyrum ovatum and $M$. nervosum show fibre-tracheids but no pseudo-tori in the material examined in this study. Further sampling is necessary since we only studied two species of Myxopyrum.

Our observations of pseudo-tori in seven genera of Oleaceae seem to support the idea that pseudo-tori are quite common among angiosperms, as was also suggested by previous studies on Ericaceae and Rosales (Rabaey et al. 2006; Jansen et al. 2007). Detailed wood anatomical studies on Oleaceae and Ericaceae did not comment on the distribution of pseudo-tori (Baas et al. 1988; Lens et al. 2004a, b). This is most likely because pit membrane thickenings are very small and easily overlooked. Relatively thin sections $(10-15 \mu \mathrm{m})$ and the use of a $100 \times$ immersion oil-objective are generally required for their detection when using a light microscope.

There is no obvious link between the presence of pseudo-tori and ecological aspects such as growth form, and a deciduous or evergreen habitat. Furthermore, it is doubtful 
whether pseudo-tori show any clear systematic significance. Their distribution can be variable within a genus, as is illustrated for instance in species of Forsythia, Jasminum, and Ligustrum. Nevertheless, the distribution of pseudo-tori within Oleaceae may suggest that it is a primitive feature with a distribution in the Fontanesieae, Forsythieae, Jasmineae, and the Ligustrinae clade of the tribe Oleeae according to Wallander and Albert (2000) (Fig. 19). Although this topology has several unresolved clades, Ligustrinae take a sister position to the remaining clades of Oleeae. Myxopyreae are sister to the other Oleaceae genera in Lee et al. (2007). Due to a smaller sampling in that study, no clear conclusions can be made. Although there are clear ultrastructural similarities between the pseudo-tori observed in Oleaceae and other angiosperm families, it would be useful to obtain more details about their chemical composition and development. To date, developmental data of pseudo-tori are limited to one Pyrus species and two Sorbus species (Barnett 1987a, b; Lachaud \& Maurousset 1996).

\section{Functional aspects}

The function of tori in pit membranes of gymnosperms has received much attention and is fairly well understood (Bailey 1913; Pittermann et al. 2005). Similar ideas about the role of tori in angiosperms have been suggested: tori could offer narrow tracheary elements the functional advantage of a higher resistance to cavitation and thus may provide an extra safety against air-seeding (Wheeler 1983; Dute et al. 1990, 2001; Carlquist 1996; Jansen et al. 2004, 2007). Narrow tracheary elements with torus-bearing pits in the latewood of elm species have been illustrated to be very resistant to embolism formation (Ellmore \& Ewers 1985; SJ, unpubl. data). However, experimental evidence demonstrating the potentially higher hydraulic resistance and air-seeding thresholds of pit membranes with tori is still missing.

It is more difficult to speculate on the possible function of pseudo-tori. In any case, pseudo-tori have most likely not the same purpose as tori, because pseudo-tori do not take a central position on the pit membrane, have a highly variable structure, and are inconsistently present within a cell. The most obvious function could be related to the presence of abundant plasmodesmata, which allow intercellular communication and transport of water, nutrients, and other molecules (Epel 1994; Haywood et al. 2002; Roberts \& Oparka 2003). A possible function was suggested by Barnett (1987a), who stated that the thickenings may play a role in cell differentiation since the cap-like thickenings could prevent or delay passage of autolytic enzymes. This was contradicted by Lachaud and Maurousset (1996), who observed plasmodesmata crossing the cap. As far as we know, no developmental differences have been observed between fibretracheids with or without pseudo-tori.

\section{CONCLUSION}

Pit membrane thickenings are much more abundant than previously assumed. Two morphologically distinct types can be easily distinguished in Oleaceae. New records of tori in Chionanthus retusa and the two Picconia species are presented and the presence of tori is confirmed for Osmanthus fragrans. Pseudo-tori are observed in several spe- 
cies of Abeliophyllum, Fontanesia, Forsythia, Jasminum, Ligustrum, Menodora, and Syringa. The inconsistent distribution of tori and pseudo-tori, even within one genus, suggests the plastic and non-homologous nature of pit membrane thickenings. More ultrastructural work and physiological experiments on pseudo-torus-bearing species are necessary to clarify the function and homology of pseudo-tori.

\section{ACKNOWLEDGEMENTS}

We thank Dr. Roland Dute (Auburn University, USA) for useful suggestions and discussion on tori in Oleaceae and Annelies Pletsers (Royal Botanic Gardens, Kew) for assistance with the preparation of samples for SEM and TEM. Prof. J. Rammeloo from the National Botanic Garden of Belgium and Dr. H. Beeckman from the Royal Museum for Central Africa are acknowledged for the supply of wood samples. We thank SYNTHESYS for financial support to DR (GB-TAF-3115). Research at the Laboratory of Plant Systematics is supported by research grants from the K.U. Leuven (OT/05/35) and the Fund for Scientific Research-Flanders (Belgium) (G.0268.04 and G.0250.05). FL is a postdoctoral fellow of the Fund for Scientific Research-Flanders (Belgium). Financial support to SJ was provided by a research grant from the Royal Society (2006/Rl) and NERC (NE/E001122/1).

\section{REFERENCES}

Baas, P., P.M. Esser, M.E.T. van der Westen \& M. Zandee. 1988. Wood anatomy of the Oleaceae. IAWA Bull. n.s. 9: 103-182.

Bailey, I.W. 1913. The preservation treatment of wood. II. The structure of the pit membranes in tracheids of conifers and their relation to the penetration of gases, liquids, and finely divided solids into green and seasoned wood. For. Quart. 11: 12-20.

Barnett, J.R. 1982. Plasmodesmata and pit development in secondary xylem elements. Planta 155: 251-260.

Barnett, J.R. 1987a. The development of fibre-tracheid pit membranes in Pyrus communis L. IAWA Bull. n.s. 7: 195-220.

Barnett, J.R. 1987b. Changes in the distribution of plasmodesmata in developing fibre-tracheid pit membranes of Sorbus aucuparia L. Ann. Bot. 59: 269-279.

Carlquist, S. 1996. Wood, bark, and stem anatomy of Gnetales: A summary. Int. J. Plant Sci. 157: S58-S76.

Choat, B., M. Ball, J. Luly \& J. Holtum. 2003. Pit membrane porosity and water stress-induced cavitation in four co-existing dry rainforest tree species. Plant Physiol. 131: 41-48.

Choat, B., T.W. Brodie, A.R. Cobb, M.A. Zwieniecki \& N.M. Holbrook. 2006. Direct measurements of intervessel pit membrane hydraulic resistance in two angiosperm tree species. Amer. J. Bot. 93: 993-1000.

Choat, B., A. Cobb \& S. Jansen. 2008. Structure and function of bordered pits: new discoveries and impacts on whole plant hydraulic function. New Phytol. 177: 608-626.

Choat, B., S. Jansen, M. A. Zwieniecki, E. Smets \& N.M. Holbrook. 2004. Changes in pit membrane porosity due to deflection and stretching: The role of vestured pits. J. Exp. Bot. 55: $1569-1575$.

Coleman, C.M., B.L. Prather, M. J. Valente, R.R. Dute \& M.E. Miller. 2004. Torus lignification in hardwoods. IAWA J. 25: 435-448.

Dute, R.R., S. Jansen, C. Holloway \& K. Paris. 2008. Torus-bearing pit membranes in selected species of the Oleaceae. J. Alabama Acad. Sci. 79: 12-22.

Dute, R.R., A.L. Martin \& S. Jansen. 2004. Intervascular pit membranes with tori in wood of Planera aquatica J.F. Gmel. J. Alabama Acad. Sci. 75: 7-21. 
Dute, R.R., M.E. Miller \& R.R. Carollo. 2001. Intervascular pit structure in selected species of Thymelaeaceae. J. Alabama Acad. Sci. 72: 14-26.

Dute, R.R. \& A.E. Rushing. 1988. Note on torus development in the wood of Osmanthus americanus (Oleaceae). IAWA Bull. n.s. 9: 41-51.

Dute, R.R. \& A.E. Rushing. 1990. Torus structure and development in the wood of Ulmus alata Michx., Celtis laevigata Wild., and Celtis occidentalis L. IAWA Bull. n.s. 11: 71-83.

Dute, R.R., A.E. Rushing \& J.D. Freeman. 1992. Survey of intervessel pit membrane structure in Daphne species. IAWA Bull. n.s. 13: 11-123.

Dute, R.R., A.E. Rushing \& J.W. Perry. 1990. Torus structure and development in species of Daphne. IAWA Bull. n.s. 11: 401-412.

Ellmore, G.S. \& F.W. Ewers. 1985. Hydraulic conductivity in trunk xylem of elm, Ulmus americana. IAWA Bull. n.s. 6: 303-307.

Epel, B.L. 1994. Plasmodesmata - composition, structure and trafficking. Plant Mol. Biol. 26 $1343-1356$.

Haywood, V., F. Kragler \& W. J. Lucas. 2002. Plasmodesmata: Pathways for protein and ribonucleoprotein signalling. Plant Cell 14: S303-S325.

IAWA Committee. 1989. IAWA List of microscopic features for hardwood identification. IAWA Bull. n.s. 10: 219-332.

Jansen, S., P. Baas, P. Gasson, F. Lens \& E. Smets. 2004b. Variation in xylem structure from tropics to tundra: Evidence from vestured pits. PNAS 101: 8833-8837.

Jansen, S., B. Choat, S. Vinckier, F. Lens, P. Schols \& E. Smets. 2004a. Intervascular pit membranes with a torus in the wood of Ulmus (Ulmaceae) and related genera. New Phytol. 163: 51-59.

Jansen, S., P. Kitin, H. De Pauw, M. Idris, H. Beeckman \& E. Smets. 1998. Preparation of wood specimens for transmitted light microscopy and scanning electron microscopy. Belg. J. Bot. 131: 41-49.

Jansen, S., Y. Sano, B. Choat, D. Rabaey, F. Lens \& R.R. Dute. 2007. Pit membranes in tracheary elements of Rosaceae and related families: New records of tori and pseudo-tori. Amer. J. Bot. 94: 503-514.

Johnson, L.A.S. 1957. A review of the family Oleaceae. Contributions from the New South Wales National Herbarium 2: 395-418.

Lachaud, S. \& L. Maurousset. 1996. Occurrence of plasmodesmata between differentiating vessels and other xylem cells in Sorbus torminalis L. Crantz and their fate during xylem maturation. Protoplasma 191: 220-226.

Lee, H.L, R.K. Jansen, T.W. Chumley \& K.J. Kim. 2007. Gene relocations within chloroplast genomes of Jasminum and Menodora (Oleaceae) are due to multiple, overlapping inversions. Mol. Biol. Evol. 24: 1161-1180.

Lens, F., K.A. Kron, J.L. Luteyn, E. Smets \& S. Jansen. 2004a. Comparative wood anatomy of the blueberry tribe (Vaccinieae, Ericaceae s.1.). Ann. Missouri Bot. Gard. 91: 566-592.

Lens, F., J.L. Luteyn, E. Smets \& S. Jansen. 2004b. Ecological trends in the wood anatomy of Vaccinioideae (Ericaceae s.1.). Flora 199: 309-319.

Liese, W. \& I. Johann. 1954. Experimentelle Untersuchungen über die Feinstruktur der Hoftüpfel bei den Koniferen. Naturwissenschaften 41: 579-579.

Ohtani, J. \& S. Ishida. 1978. Pit membrane with torus in dicotyledonous woods. J. Jap. Wood Res. Soc. 24: 673-675.

Parameswaran, N. \& W. Liese. 1973. Anomalous structures in bordered pits of fibre-tracheids of Ribes sanguineum. Wood and Fiber 5: 76-79.

Parameswaran, N. \& A. Vidal Gomes. 1981. Fine structural aspects of helical thickenings and pits in vessels of Ligustrum lucidum Ait. (Oleaceae). IAWA Bull. n.s. 2: 179-185. 
Patel, R.N. 1978. Wood anatomy of the dicotyledons indigenous to New Zealand. II. Oleaceae. N.Z. J. Bot 16: 1-6.

Pittermann, J., J.S. Sperry, U.G., Hacke, J.K. Wheeler \& E.H. Sikkema. 2005. Torus-margo pits help conifers compete with angiosperms. Science 310: 1924.

Rabaey, D., F. Lens, E. Smets \& S. Jansen. 2006. The micromorphology of pit membranes in tracheary elements of Ericales: new records of tori or pseudo-tori? Ann. Bot. 98: 943-951.

Roberts, A.G. \& K. J. Oparka. 2003. Plasmodesmata and the control of symplastic transport. Plant Cell Environ 26: 103-124.

Sano, Y. 2005 Inter- and intraspecific structural variations among intervascular pit membranes as revealed by field-emission scanning electron microscopy. Amer. J. Bot. 92: 1077-1084.

Sano, Y. \& S. Jansen. 2006. Perforated pit membranes in imperforate tracheary elements of some angiosperms. Ann. Bot. 97: 1045-1053.

Schols, P., S. Dessein, C. D'Hondt, S. Huysmans \& E. Smets. 2002. CARNOY: a new digital measurement tool for palynology. Grana 41: 124-126.

Stearn, W.T. 1976. Union of Chionanthus and Linociera (Oleaceae). Ann. Missouri Bot. Gard. 63: $355-357$.

Wallander, E. \& V.A. Albert. 2000. Phylogeny and classification of Oleaceae based on rps16 and trnL-F sequence data. Amer. J. Bot. 87: 1827-1841.

Wheeler, E.A. 1983. Intervascular pit membranes in Ulmus and Celtis native to the United States. IAWA Bull. n.s. 4: 79-88.

Wheeler, J.K., J.S. Sperry, U.G. Hacke \& N. Hoang. 2005. Intervessel pitting and cavitation in woody Rosaceae and other vesselled plants: a basis for a safety versus efficiency trade-off in xylem transport. Plant Cell Environ. 28: 800-812. 